\title{
Using Card Sorts for Understanding Website Information Architectures: Technological, Methodological and Cultural Issues
}

\author{
Helen Petrie, Christopher Power, Paul Cairns, and Cagla Seneler \\ Department of Computer Science, University of York \\ \{Helen.Petrie, cpower, pcairns, caglaos\}@cs.york.ac.uk
}

\begin{abstract}
The card sort technique has many uses in HCI research and practice. Card sorts have traditionally been conducted with physical cards but now programs are available for this task. It is unclear if results from an online version of this technique are as reliable as the "oncard" version. This paper presents a study comparing oncard and online versions of the card sort technique for card set reflecting the information architecture (IA) of two website domains (museum and news sites). No differences were found between the two versions. However, the online version took significantly longer for participants than the oncard version, particularly for non-native English speakers. The card sort technique was also able to reveal cultural differences between mental models of British, Chinese and Indian participants of the IAs of both museum and news websites and showed that all participants have mental models that differ substantially from the typical IAs of websites in these domains.
\end{abstract}

Keywords: card sort, online card sort program, evaluation methodology, information architecture, website design, museum websites, news websites, cultural differences.

\section{Introduction}

The card sort technique has many uses in HCI research and practice $[6,15]$. In its simplest form it involves asking participants to sort a set of cards with words or pictures on them into groups of cards that are similar. Participants may be asked to provide labels for the groups of cards they have created or they may be provided with pre-defined labels and asked to match the cards to these labels. Card sorts in which participants define the groups are termed open card sorts, those in which the investigator provides the groups are terms closed card sorts [16].

Card sorting is a simple way of gaining insight into the participants' categorizations and mental models of the items represented on the cards. For example, it can assist in the development of the information architecture (IA) of websites, if participants are given cards with the different topics the website is to cover [10].

Although the technique is simple to administer to individual participants, the preparation of cards and the subsequent analysis of the data can be quite tedious and 
time consuming. It is also easy to make mistakes (as we have found to our cost during this research), particularly if the number of cards in the sort is large. Cards can be mis-numbered, mis-placed or not recorded after the sort, resulting in loss of data.

Card sorts have traditionally been conducted with physical cards but now programs are available (often via the Web) to conduct card sorts virtually, for example on a webpage. This potentially saves time and effort for both participants and investigators $[4,19]$ and cuts down on the potential for mistakes. We will refer to the two methods as "oncard" and "online" card sorts. Although online card sorts clearly have advantages, do online card sort programs provide the same experience for participants? Anecdotal evidence suggests that online programs (WebSort, XSort, UXSort, Optimal Sort), although they are all relatively easy and clear to use, do not provide quite the same participant experience of being able to move the cards around, look at a card in comparison with one group, then in comparison with another group, and so on. The interaction with tangible objects such as cards is something very natural, which has not yet been completely replaced by virtual experiences. However, does this difference have any effect on the results of card sort studies?

Two studies have investigated the difference between oncard and online card sorts. Harper et al [7] developed their own card sort program and then evaluated it by comparing the program with traditional oncard sorts. 108 participants undertook two open card sorts each, either oncard - oncard, online - oncard, oncard - online, or online - online. Only one set of 33 card items was used, so participants undertook the second card sort with the same card set after a 15 minute distractor task. Although no significant differences were found between oncard and online versions, the fact that participants repeated the sort after only 15 minutes suggests that the results of the second sort would have been contaminated by the first sort.

Bussolon et al [3] also compared oncard and online card sorts, using Netsorting (http://www.cardsorting.info/) for the online sorts. A between participants design was used, with each participant undertaking two card sorts either both online or both oncard. Data from 60 participants were analysed. One set of cards for sorting was of animals (mammals, reptiles, fish, birds) which seems a very easy sort to undertake; the other set was of "gifts", but no information is provided about the items in this card set. This study used a closed card sort, which is much less common than the open sort and thus the results are less useful. Again no significant differences were found between the oncard and online sorts, but this study is not fully satisfactory in its comparison of the two versions of the technique.

A further question of interest is how many participants are needed to establish a statistically reliable card sort and whether this differs between oncard and online sorts. Tullis and Wood [17] had 168 participants undertake a card sort of 46 cards with an online program (WebSort, http://websort.net/). They then compared the card sort results of 10 samples each of size 2, 5, 8, 12, 15, 20, 30, 40, 50, 60, and 70 participants with the card sort results of the full participant set. They found that with 30 participants there was a $95 \%$ correlation with the full card sort and increasing the number of participants beyond 30 provided little increase in the size of the correlation coefficient.

Both Bussolon et al [3] and Tullis and Wood [17] use correlations between the similarity matrices between the cards in two sorts to establish the relationship between the oncard and online sorts and the number of participants needed for a 
reliable sort. Unfortunately, data in similarity matrices from card sorts is very likely to violate the assumptions for the correlation. In particular, a correlation between variables $\mathrm{X}$ and $\mathrm{Y}$ assumes that the variance of $\mathrm{Y}$ for each value of $\mathrm{X}$ is constant, or at least similar (assumption of homogeneity of variance in arrays) [9]. This is not the case for correlations between two card sorts, as some cards always get grouped together and others never get grouped together, leading to a gradation in variance. This violation may not have a substantial effect on the correlation between card sorts, but in our experience obscured small differences between sorts. In this paper we explore the use of the minimum edit distance [5] to compare card sorts.

A final question of interest is whether card sorts can help highlight cultural differences in the mental models of participants, particularly in relation to the IA of websites. There is a small but growing body of research and guidelines on how to vary websites for users from different cultures [2,7], although the guidelines do not mention variations in information architecture. Kralisch, Yeu and Jali [11] used card sorts to investigate the differences between British, German, Malaysian and Russian participants in their understanding of medical terms that might be used in health information websites. They found numerous differences between the four cultural/linguistic groups. Qu et al [14] used card sorts to investigate the differences between the groupings of wedding related images by Chinese and Danish participants. Wan Abdul Rahim, Noor and Aidid [18] were also interested in cultural differences in website information architecture, although they used a questionnaire based on their own and Hofstede's [8] theories of cultural differences to explore Muslim participants' preferences for different information architectures. In our own research [13], we have found that English and Chinese web users preferred different navigation layouts on websites, but it is not clear whether this effect would extend to other aspects of IA.

We therefore conducted a study comparing oncard and online card sorting methods with two different card sorts relating to IAs of websites to address the following questions:

- $\quad$ are the cards sorts produced oncard and online any different from each other?

- is the participant experience equivalent in undertaking a card sort exercise online and with physical cards?

- is an online card sort more efficient for both researchers and participants than an oncard card sort?

- can card sorts reveal cultural differences in participants' categorizations and mental models of the IA of two types of websites?

\section{Method}

In order to investigate these questions, a two by two non-factorial between participants study was undertaken. Each participant undertook two different card sorts, one online and one oncard, with one being about the IA of news websites and the other being about the IA of museum websites. 


\subsection{Participants}

A total of 218 participants took part in the study, comprising students from two undergraduate modules and one graduate module on interactive systems in the Department of Computer Science at the University of York. There were 188 male and 30 female participants, aged between 18 to 35 years, with a mean age of 21.3 years. Within the participant group there were 116 who were native speakers of English, 102 were native speakers of a variety of other languages.

Of the 102 students who spoke English as a second language the average selfreported proficiency in English was 5.4 on a 7 point scale, with 7 being "Very Proficient" to 1 "Not at all Proficient". The students came from a variety of nonEnglish speaking cultural backgrounds including: Chinese, Taiwanese, Indian, other European cultural groups including Polish, German and Greek, Middle-Eastern, and sub-Saharan Africa.

Participants undertook the study as part of the practical assignments for their module. However, to motivate student participation, there was a lottery draw for three $£ 10$ gift vouchers for a major online book retailer for those who completed the assignment.

\subsection{Equipment and Materials}

For creation of the word sets to be used in the card sorts, a survey was undertaken of 10 news websites and 18 museum websites from countries with a national language of English (Australia, Canada, UK, USA). For each website the top level IA menu was recorded. From the words within these menus the top 7 most commonly occurring words were chosen as base categories for collecting the sets of words for each website domain.

Each website was visited again and the IA under each of the 7 categories was recorded and grouped together according to their meaning. For example, if material on personal finance was labelled as "Finances" on one news website while on another it was "Your money", these were recorded under one group "Personal Finance" and as occurring on 2 distinct websites. When complete, the top groups that occurred in the majority of the websites under the 7 categories were selected as words for the card sort. The news sites produced a set of 50 words while museums produced a set of 40 words fitting these criteria. These groups are referred to subsequently as the "a priori" groups.

Within each set of words, each word was given a distinct number. The words were printed onto sets of cards sized $89 \mathrm{~mm}$ x $51 \mathrm{~mm}$ and each word's associated number was recorded on the back of the card.

The online card sort was prepared the online card sorting package WebSort (http://www.websort.net). Two different online card sorts, one for news websites and one for museum websites, were created. Each word was entered into the WebSort software in the same order as the number assigned to the cards to ensure that cards could be matched during analysis. The online sort was set to request a participant number to allow matching of online sorts with the respective oncard sorts for each participant. The online sort was set such that it would randomize the order of presentation of the cards for each participant and so that participant results would only 
be recorded if all cards were sorted and the categories into which they were sorted were labelled.

A questionnaire regarding the participants' cultural background, language proficiency and other demographic information was prepared in the online survey package QuestionPro (www.questionpro.com).

All computer based tasks were undertaken in computer labs within the Department of Computer Science at the University of York, with participants undertaking the tasks in their preferred web browser (e.g. Firefox, Internet Explorer, Opera) and their preferred operating system (e.g. Windows, Linux).

Tickets with participant numbers and a sheet recording which order of conditions each number should undertake were prepared for the participants. The order of conditions for participants were created through a complete counterbalancing of the two conditions, online versus oncard and museum versus news. After each session the counterbalancing was adjusted by the researchers to account for missing data points from participants who failed to complete all the components of the study.

\subsection{Procedure}

Data collection sessions took place during the practical class periods of each module that participated. On arrival at the class each participant was given a lottery ticket to serve as their participant number during the session (and as their number in the prize draw) and a sheet of instructions. The practical leaders and the researchers reviewed the instructions verbally with the participants at the beginning of the session.

The first step of the study was for the participant to fill out the questionnaire regarding their cultural background and demographic information. This questionnaire included a declaration of informed consent that included a statement that the participant could withdraw at any time without academic penalty.

Each participant was instructed to undertake two sorts, one sort on the news words and one sort on the museum words. Participants were then asked to check the counterbalance sheet for order in which they were to conduct these sorts and which sort should be undertaken online and which should be undertaken oncard.

\subsubsection{Oncard Procedure}

For oncard sorts participants were handed an envelope containing a set of cards for the condition (news or museum) they were undertaking. Participants were also given a set of blank slips of paper on which to record their category labels.

Participants started the oncard sort with the cards in a stack with words facing up. They were asked to shuffle the cards at the beginning of their sort to ensure as much randomness as possible in the placement of cards in the set. The participants were told that they were to sort the cards into categories of their choosing and label those categories with the blank sheets of paper provided. They were told that there were no correct answers, but that they should have more than one category and fewer than the maximum number of cards. They were informed that they were not to try for the fastest time possible, but that they should also not go too slowly so as to avoid indecision about categories.

The participants were timed by another member of the class for how long their sort took from the beginning of the sort to the last category being labelled. 
When the oncard sort was complete, the participant recorded the label of each category in a spreadsheet provided and then the number of the cards in each pile and the cards associated with that pile. The participants also recorded their participant lottery number and the time it took to undertake the sort in the spreadsheet.

\subsubsection{Online Procedure}

For the online sort participants were instructed to go to the web address for the sort they were assigned to undertake. On arriving at the website the participant was presented with a dialog box requesting their participant number. After this, the website presented the same instructions as those described for the oncard sort.

At the end of the sort, the participants' labelled categories, the pile names and their time performing the sort were automatically recorded by the website.

\subsection{Data Preparation and Analysis}

Due to the need to combine a variety of sources of data for participants, specifically demographic data, online sort data and oncard sort data, a bespoke piece of software was written to aggregate and clean the data for each participant. This software was developed using a test-driven development methodology [1] with each iteration of development identifying errors in the data that could be automatically identified and removed. After applying the final software suite to the data, participants who had any of the following errors in their data (all of which occurred), usually the result of input errors in the oncard spreadsheets, were removed from the datasets:

- sorts where the participant number and demographics were missing from the questionnaire results;

- $\quad$ sorts with cards missing in the recording of either card set;

- $\quad$ sorts with duplicate cards recordings;

- $\quad$ sorts where the number of cards recorded in each pile was not equal to the actual number of cards in the pile;

- $\quad$ sorts where category names were repeated.

For each card sort data set a hierarchical cluster analysis [9] was conducted to extract the average grouping of the cards by the relevant set of participants, these groupings will be termed card groups. This analysis uses a similarity matrix of the number of times each card in the set is grouped with each other card in the set.

In order to compare two different card sorts this paper uses the minimum edit distance [5]. This metric, which is symmetric, positive and satisfies the triangle inequality, indicates the minimum number of card changes, from one group in a sort to another group in the same sort, in order to transform one sort result into another sort result. This metric is polynomial in time complexity, $O\left(n^{3}\right)$, where $\mathrm{n}$ is the number of cards in the card set, and can be calculated by hand easily on card sorts with small numbers of cards. In this paper the minimum edit distance will be expressed as the percentage of the total cards in the card set, in order to allow comparisons of the results between two card sets of different sizes. 


\section{Results}

To investigate the question of whether the cards sorts conducted oncard were different from those conducted online, minimum edit distances between the cards sorts from all the native English speakers were compared (English speakers were used in this analysis simply to create a more homogenous data set). The results for the oncard and online sorts were compared with each other and also compared with the a priori groups. The results are shown in Tables 1 and 2 .

The first result of note is that for both card sets, but particularly for the news card set, both the oncard and online sorts produced groups that were substantially different from the a priori card set, although the latter reflects the average organization of items on a set of real web sites. In the case of the museum card set, $27.5 \%$ of cards were grouped differently in the oncard sort compared to the a priori groups and $22.5 \%$ of cards were grouped differently in the online sort compared to the a priori card set. The situation was even more extreme with the news card set, with $36.0 \%$ of cards grouped differently for both the oncard and online sort compared to the a priori groups. This suggests that young English speaking participants (almost all of whom were British) do not have the same mental models of museum and news categories as those who develop websites in these areas.

Tables 3 and 4 show the differences in groups between the a priori, oncard and online sorts for museum and news card sets respectively. In the museum set, it can be seen that there were a number of differences in which cards were placed in particular groups, but in particular, in both the oncard and online sort, the participants produced an additional group ("Family activities'), that did not occur in the a priori groups. In the news set, participants produced fewer groupings than the a priori set. The "Business" and "Lifestyle" groups did not appear at all in the participants' sorts. In addition, the classic news categories of factual and opinion pieces were very blurred in the participants' sorts.

Table 1. Minimum edit distance (\%) between a priori, oncard, and online card sorts for museum card set for native English speakers

\begin{tabular}{lccc}
\hline & A priori & $\begin{array}{c}\text { Oncard } \\
(\mathbf{N = 4 6})\end{array}$ & $\begin{array}{c}\text { Online } \\
(\mathbf{N}=\mathbf{5 4})\end{array}$ \\
\hline A priori & - & 27.5 & 22.5 \\
\hline Oncard & 27.5 & - & 7.5 \\
\hline Online & 22.5 & 7.5 & - \\
\hline
\end{tabular}

Table 2. Minimum edit distance (\%) between a priori, oncard, and online card sorts for news card set for native English speakers

\begin{tabular}{lccc}
\hline & A priori & $\begin{array}{c}\text { Oncard } \\
(\mathbf{N = 3 0 )}\end{array}$ & $\begin{array}{c}\text { Online } \\
(\mathbf{N}=\mathbf{5 2})\end{array}$ \\
\hline A priori & - & 36.0 & 36.0 \\
\hline Oncard & 36.0 & - & 6.0 \\
\hline Online & 36.0 & 6.0 & - \\
\hline
\end{tabular}


Table 3. Museum card set: a priori groups, oncard and online sorts

\begin{tabular}{|c|c|c|}
\hline A priori groups & Oncard groups & Online groups \\
\hline $\begin{array}{l}\text { Exhibitions } \\
\text { Current exhibitions } \\
\text { Future exhibitions } \\
\text { Past exhibitions } \\
\text { Travelling exhibitions } \\
\end{array}$ & $\begin{array}{l}\text { Exhibitions } \\
\text { Current exhibitions } \\
\text { Future exhibitions } \\
\text { Past exhibitions } \\
\text { Travelling exhibitions } \\
\end{array}$ & $\begin{array}{l}\text { Exhibitions } \\
\text { Current exhibitions } \\
\text { Future exhibitions } \\
\text { Past exhibitions } \\
\text { Travelling exhibitions } \\
\end{array}$ \\
\hline $\begin{array}{l}\text { The Collection } \\
\text { Our collections } \\
\text { Search the collection } \\
\text { Conservation } \\
\text { Online collection } \\
\text { Collections management } \\
\text { Highlights of the collection }\end{array}$ & $\begin{array}{l}\text { The Collection } \\
\text { Our collections } \\
\text { Search the collection } \\
\text { Online collection } \\
\text { Highlights of the collection }\end{array}$ & $\begin{array}{l}\text { The Collection } \\
\text { Our collections } \\
\text { Search the collection } \\
\text { Online collection } \\
\text { Collections management } \\
\text { Highlights of the collection }\end{array}$ \\
\hline $\begin{array}{l}\text { The Shop } \\
\text { Books and media } \\
\text { Prints and posters } \\
\text { Jewellery } \\
\text { Fashion and accessories } \\
\text { Homewares } \\
\text { Stationery }\end{array}$ & $\begin{array}{l}\text { Shopping and Eating } \\
\text { Books and media } \\
\text { Prints and posters } \\
\text { Jewellery } \\
\text { Fashion and accessories } \\
\text { Homewares } \\
\text { Stationery } \\
\text { Eat and drink } \\
\text { Shops }\end{array}$ & $\begin{array}{l}\text { Shopping and Eating } \\
\text { Books and media } \\
\text { Prints and posters } \\
\text { Jewellery } \\
\text { Fashion and accessories } \\
\text { Homewares } \\
\text { Stationery } \\
\text { Eat and drink } \\
\text { Shops }\end{array}$ \\
\hline $\begin{array}{l}\text { Learning } \\
\text { Schools } \\
\text { Teachers } \\
\text { Online resources } \\
\text { Adult learners } \\
\text { Activities for families } \\
\text { Learning centre }\end{array}$ & $\begin{array}{l}\text { Learning } \\
\text { Schools } \\
\text { Teachers } \\
\text { Adult learners } \\
\text { Learning centre } \\
\text { Talks and lectures } \\
\text { Courses and demonstrations }\end{array}$ & $\begin{array}{l}\text { Learning } \\
\text { Schools } \\
\text { Teachers } \\
\text { Online resources } \\
\text { Adult learners } \\
\text { Learning centre } \\
\text { Talks and lectures } \\
\text { Courses and demonstrations } \\
\text { Events calendar }\end{array}$ \\
\hline $\begin{array}{l}\text { Visiting the museum } \\
\text { Finding the museum } \\
\text { Opening times } \\
\text { Eat and drink } \\
\text { Access for disabled visitors } \\
\text { Booking tickets } \\
\text { Shop } \\
\text { Family visits }\end{array}$ & $\begin{array}{l}\text { Visiting the museum } \\
\text { Finding the museum } \\
\text { Opening times } \\
\text { Access for disabled visitors } \\
\text { Booking tickets } \\
\text { Events calendar } \\
\text { Jobs }\end{array}$ & $\begin{array}{l}\text { Visiting the museum } \\
\text { Finding the museum } \\
\text { Opening times } \\
\text { Access for disabled visitors } \\
\text { Booking tickets } \\
\text { Contact us }\end{array}$ \\
\hline $\begin{array}{l}\text { The Organization } \\
\text { Jobs } \\
\text { Contact us } \\
\text { Press Room } \\
\text { Management } \\
\text { History of the Museum } \\
\text { Mission statement } \\
\text { Volunteering at the museum }\end{array}$ & $\begin{array}{l}\text { The Organization } \\
\text { Jobs } \\
\text { Contact us } \\
\text { Press Room } \\
\text { Management } \\
\text { History of the Museum } \\
\text { Mission statement } \\
\text { Volunteering at the museum } \\
\text { Online resources } \\
\text { Conservation } \\
\text { Collections Management }\end{array}$ & $\begin{array}{l}\text { The Organization } \\
\text { Jobs } \\
\text { Press Room } \\
\text { Management } \\
\text { History of the Museum } \\
\text { Mission statement } \\
\text { Volunteering at the museum } \\
\text { Conservation }\end{array}$ \\
\hline & $\begin{array}{l}\text { Family activities } \\
\text { Events for the family } \\
\text { Activities for families } \\
\text { Family visits }\end{array}$ & $\begin{array}{l}\text { Family activities } \\
\text { Events for the family } \\
\text { Activities for families } \\
\text { Family visits }\end{array}$ \\
\hline
\end{tabular}


Table 4. News card set: a priori groups, oncard and online sorts

\begin{tabular}{lll}
\hline \multicolumn{1}{c}{ A priori groups } & \multicolumn{1}{c}{ Oncard groups } & \multicolumn{1}{c}{ Online groups } \\
\hline Arts & Arts & Arts \\
Films & Comics & Books \\
Books & Films & Comics \\
Music & Health & Films \\
Stage and Dance & Markets & Music \\
TV \& Radio & Music & News Discussions \\
Comics & News Discussions & Relationships \\
Visual Arts & Relationships & Stage and Dance \\
Markets & Stage and Dance & TV \& Radio \\
& TV \& Radio & Visual Arts \\
\hline
\end{tabular}

\begin{tabular}{|c|c|c|}
\hline $\begin{array}{l}\text { Business } \\
\text { Economics } \\
\text { Careers } \\
\text { Small Business } \\
\text { Industries } \\
\text { Personal Finance }\end{array}$ & & \\
\hline $\begin{array}{l}\text { Lifestyle } \\
\text { Food and Drink } \\
\text { Fashion and Style } \\
\text { Health } \\
\text { Family } \\
\text { Homes } \\
\text { Relationships }\end{array}$ & & \\
\hline $\begin{array}{l}\text { Money } \\
\text { Savings } \\
\text { Property } \\
\text { Taxes } \\
\text { Investments } \\
\text { Pensions } \\
\text { Borrowing } \\
\text { Insurance }\end{array}$ & $\begin{array}{l}\text { Finance } \\
\text { Books } \\
\text { Borrowing } \\
\text { Careers } \\
\text { Economics } \\
\text { Industries } \\
\text { Insurance } \\
\text { Investments } \\
\text { Pensions } \\
\text { Personal Finance } \\
\text { Property } \\
\text { Savings } \\
\text { Small Business } \\
\text { Taxes }\end{array}$ & $\begin{array}{l}\text { Finance } \\
\text { Borrowing } \\
\text { Careers } \\
\text { Economics } \\
\text { Family } \\
\text { Industries } \\
\text { Insurance } \\
\text { Investments } \\
\text { Markets } \\
\text { Pensions } \\
\text { Personal Finance } \\
\text { Property } \\
\text { Savings } \\
\text { Small Business } \\
\text { Taxes }\end{array}$ \\
\hline $\begin{array}{l}\text { News } \\
\text { National } \\
\text { World } \\
\text { Politics } \\
\text { Education } \\
\text { Science } \\
\text { Local } \\
\text { Technology }\end{array}$ & $\begin{array}{l}\text { Factual } \\
\text { Basketball } \\
\text { Columnists } \\
\text { Education } \\
\text { Family } \\
\text { Fashion and Style } \\
\text { Homes } \\
\text { Local } \\
\text { National } \\
\text { Politics }\end{array}$ & $\begin{array}{l}\text { Factual } \\
\text { Basketball } \\
\text { Columnists } \\
\text { Education } \\
\text { Fashion and Style } \\
\text { Health } \\
\text { Homes } \\
\text { Local } \\
\text { National } \\
\text { Politics }\end{array}$ \\
\hline
\end{tabular}


Table 4. (Continued)

\begin{tabular}{lll}
\hline & Factual (cont) & Factual (cont) \\
& Puzzles and Games & Puzzles and Games \\
& Science & Science \\
& World & World \\
\hline Opinion & Non-factual & Non-factual \\
Columnists & Blogs & Blogs \\
Letters to the Editor & Cartoons & Cartoons \\
Blogs & Commentators & Commentators \\
Cartoons & Corrections & Corrections \\
News Discussions & Editorials & Editorials \\
Editorials & Leading articles & Leading articles \\
Corrections & Letters to the Editor & Letters to the Editor \\
Leading articles & Technology & Technology \\
Commentators & & \\
\hline Sport & Sport & Sport \\
Football & Baseball & Baseball \\
Golf & Food and Drink & Food and Drink \\
Tennis & Football & Football \\
Motor Sport & Golf & Golf \\
Ice Hockey & Ice Hockey & Ice Hockey \\
Baseball & Motor Sport & Motor Sport \\
Basketball & Tennis & Tennis \\
\hline
\end{tabular}

However, the oncard and online card sorts produced very similar groups, with less than $10 \%$ of cards grouped differently in either sort $(7.5 \%$ for the museum set, $6.0 \%$ for the news set). This shows that the oncard and online procedures produce equivalent sorts, so the different technology does not affect the outcome. It also supports the finding that the groups produced by participants are different from the a priori groups, as both the oncard and online produced the same set of groups, although different from the a priori groups.

To investigate one aspect of the user experience of undertaking a card sort, and also to investigate the efficiency of oncard and online sorts, the times taken to complete the card sorts using the two versions of the technique were analysed. For this analysis, data from the native and non-native speakers of English were considered separately, as it was thought that the non-native speakers may take longer to do the card sorts both oncard and online, as they would need to think about the words more. Two independent measures two way analyses of variance were calculated, one each for the museum and news sorts, on the time taken to complete the sort with the following variables: Sort version (oncard vs online) and Language (native English speaker vs non-native English speaker). For both sorts there was a significant difference between the sort versions (for museum: $\mathrm{F}=12.92$, $\mathrm{df}=1,182, \mathrm{p}<0.001$; for news: $\mathrm{F}=6.60, \mathrm{df}=1,153, \mathrm{p}<0.01$ ), with oncard sorts producing significantly shorter times than online sorts. There was also a significant difference between native and non-native speakers of English, as predicted (for museum: $\mathrm{F}=43.75$, $\mathrm{df}=1,182$, $\mathrm{p}<0.001$; for news: $\mathrm{F}=25.48, \mathrm{df}=1,153, \mathrm{p}<0.001$ ), with native speakers producing significantly shorter times than non-native speakers. Finally there was a significant 
interaction between the effects of sort version and user group (for museum: $\mathrm{F}=6.74$, $\mathrm{df}=1,182, \mathrm{p}<0.01$; for news: $\mathrm{F}=25.48$, $\mathrm{df}=1,153, \mathrm{p}<0.001)$. These interactions are illustrated in Figures 1 and 2, which show that for the non-native speakers of English, the time increase for online compared to oncard is magnified.

To investigate whether card sorts would show cultural differences in the mental models of participants of the IAs for the two website domains, card sorts from participants from the following cultural groups were compared: British (we use British to indicate the cultural group, English to indicate the language group), Chinese and those from the Indian sub-continent. The results are shown in Table 5 and 6 . The Indian sorts are even more different from the a priori than the British sorts $(40.0 \%$ for museums and $42.0 \%$ for news). For the Chinese sort, the museum sort is closer to the a priori groups than the British (although the number of participants in this group is only 16 , so we have less confidence in this sort than the others, for which the numbers are higher), although the news sort is less similar to the a priori than the British (38.0\%).

For the museum set, the number and general nature of groups produced by the British, Indian and Chinese sorts are the same. However, the particular cards grouped together are rather different for some of the groups. In particular, the cards in the groups "The organization" and "Visiting the museum" differ considerably (space does not permit us to reproduce the full groups in this analysis, but they are available from the authors). The Indian sort produced a larger group for "Visiting the museum" with a number of cards from the a priori group "The organization" included in it. Conversely, the Chinese sort included more cards in the "The organization" rather than in "Visiting the museum".

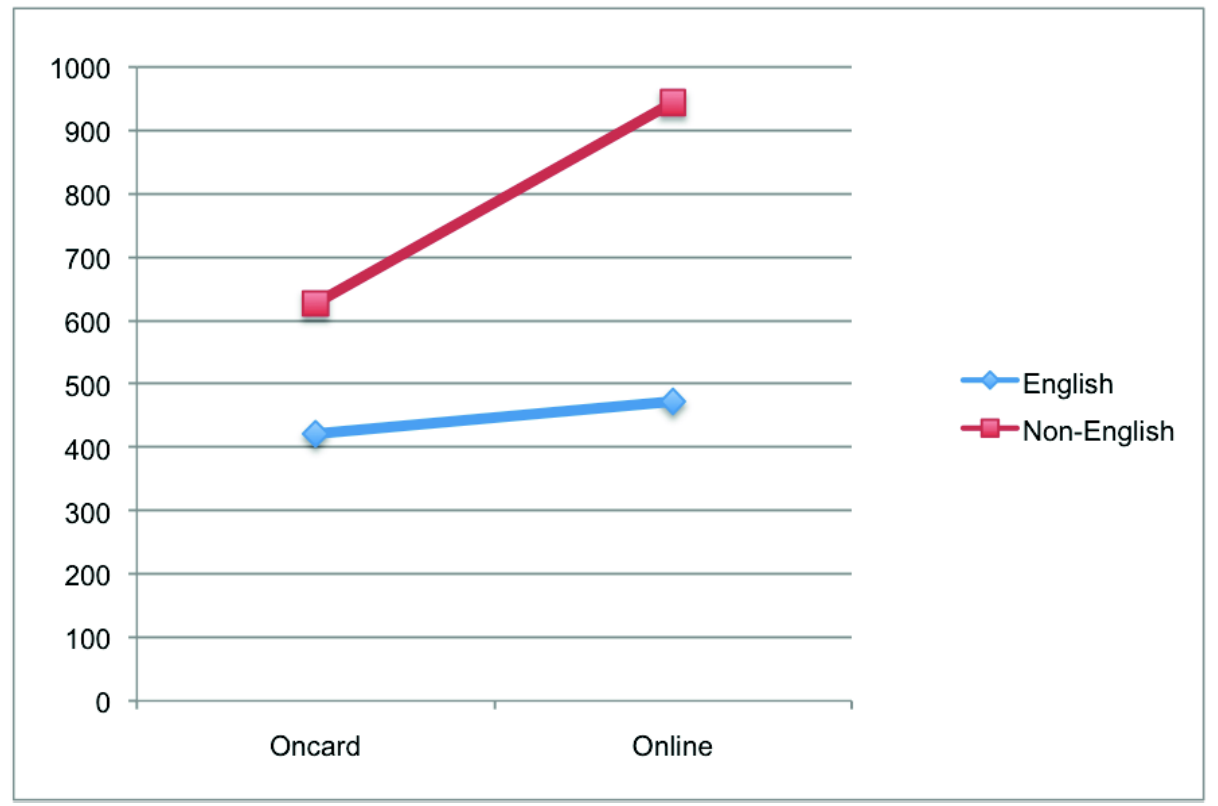

Fig. 1. Mean time (seconds) to complete museum card sort oncard and online for native English speakers and non-native English speakers 


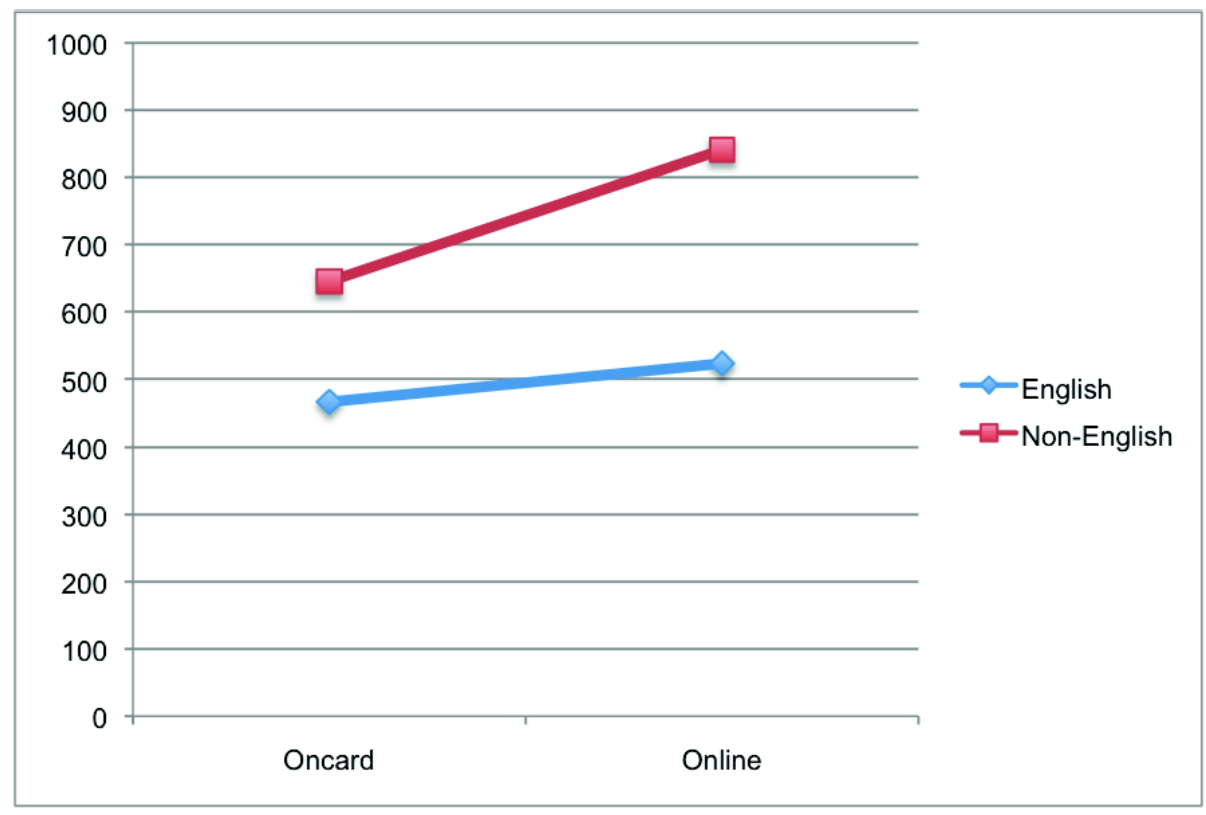

Fig. 2. Mean time (seconds) to complete news card sort oncard and online for native English speakers and non-native English speakers

Table 5. Minimum edit distance between card sorts by British, Chinese, and Indian participants for museum card set

\begin{tabular}{lcccc}
\hline & A priori & $\begin{array}{c}\text { British } \\
(\mathbf{N = 1 0 0})\end{array}$ & $\begin{array}{c}\text { Indian } \\
(\mathbf{N}=\mathbf{2 4})\end{array}$ & $\begin{array}{c}\text { Chinese } \\
(\mathbf{N = 1 6})\end{array}$ \\
\hline A priori & - & 25.0 & 40.0 & 22.5 \\
\hline British & 25.0 & - & 15.0 & 15.0 \\
\hline Indian & 40.0 & 15.0 & - & 30.0 \\
\hline Chinese & 22.5 & 15.0 & 30.0 & - \\
\hline
\end{tabular}

Table 6. Minimum edit distance between card sorts by British, Chinese, and Indian participants for news card set

\begin{tabular}{lcccc}
\hline & A priori & $\begin{array}{c}\text { British } \\
(\mathbf{N = 8 2})\end{array}$ & $\begin{array}{c}\text { Indian } \\
(\mathbf{N = 2 1})\end{array}$ & $\begin{array}{c}\text { Chinese } \\
(\mathbf{N = 2 0})\end{array}$ \\
\hline A priori & - & 34.0 & 42.0 & 38.0 \\
\hline British & 34.0 & - & 14.0 & 18.0 \\
\hline Indian & 42.0 & 14.0 & - & 16.0 \\
\hline Chinese & 38.0 & 18.0 & 16.0 & - \\
\hline
\end{tabular}


For the news set, the number and nature of groups produced by the three cultural sorts varied. The British sort produced six groups, whereas the Indian and Chinese sorts produced only five groups each. All sorts produced similar groups for "Money and business", "Sports" and "Factual news". However, the British sort produced groups for "Opinion", "Arts" and "Non-factual", whereas the Indian and Chinese sorts produced "Entertainment" and "Non-factual" with rather different groupings of particular cards.

\section{Discussion and Conclusions}

This study has shown a number of interesting results about the card sort technique and its use. In spite of anecdotal evidence, we found no difference between conducting card sorts on physical cards and using an online program (oncard versus online) with respect to the reliability of the results. Less than $10 \%$ of cards were grouped differently and the groups which emerged were the same. This finding is in line with previous studies by Bussolon et al [3] and Harper et al [7]. However, both oncard and online sorts produced groups from English speaking participants which were substantially different from the a priori groups, although the latter were based on an analysis of a substantial number of websites in each of the two domains. This suggests that website designers in these domains might do well to study their audiences more carefully, and possibly use card sort studies to elicit the mental models of these audiences.

A further unexpected result emerged from the times taken for participants to complete card sorts that were significantly longer using the online program than with physical cards. This effect was significantly more pronounced for non-native speakers of English. Thus the online version of the card sort technique may well save time and effort for researchers and practitioners but the time for each participant is significantly longer than with physical cards. Researchers and practitioners need to consider the balance of importance between these two factors.

Finally, the study showed that the card sort technique can be used successfully to reveal cultural differences in the mental models of information architectures of website domains. Interesting and meaningful differences were found between British, Chinese and Indian participants in their average groupings of cards relating to both museum and news website information architectures.

In further analyses, we will investigate the number of participants required to establish a stable card sort using the minimum edit distance statistic. This may produce different results from those proposed by Bussolon et al [3] and Tullis and Wood [17], which were based on correlation analyses.

This study has confirmed a number of interesting and useful facts about the card sort technique and its usefulness in the HCI domain. In addition, it has revealed that this seemingly simple tool can be used to draw out subtle and meaningful information about users and their mental models. Thus, it is important to expose new researchers and practitioners in its application in the design of interactive systems.

\section{References}

1 Astels, D.: Test Driven Development: A Practical Guide. Prentice Hall Professional Technical Reference (2003)

2 Aykin, N., Quaet-Faslem, P.H., Milewski, A.E.: Cultural ergonomics. In: Salvendy, G. (ed.) Handbook of Human Factors and Ergonomics, 3rd edn. John Wiley and Son, New Jersey (2006) 
3 Bussolon, S., Russi, B., del Missier, F.: Online card sorting: as good as the paper version. In: Proceedings of the 13th European Conference on Cognitive Ergonomics: Trust and Control in Complex Socio-Technical System (ECCE 2006). ACM Press, New York (2006)

4 Chaparro, B.S., Hinkle, V.D., Riley, S.K.: The usability of computerized card sorting: a comparison of three applications by researchers and end users. Journal of Usability Studies 4(1), 31-48 (2008)

5 Deibel, K., Anderson, R., Anderson, R.: Using edit distance to analyze card sorts. Expert Systems 22(3), 129-138 (2005)

6 Fincher, S., Tenenberg, J.: Making sense of card sorting data. Expert Systems 22(3), 89-93 (2005)

7 Harper, M.E., Jentsch, F., van Duyne, L.R., Smith-Jentsch, K., Sanchez, A.D.: Computerized card sort training tool: is it comparable to manual card sorting? In: Proceedings of the Human Factors and Ergonomics Society 46th Annul Meeting, pp. 2049-2053 (2002)

8 Hofstede, G., Hofstede, G.J.: Cultures and organizations: software of the mind (Revised and expanded 2nd edn.). McGraw-Hill, New York (2005)

9 Howell, D.C.: Statistical methods for psychology, 6th edn. Thomson, Wadsworth (2007)

10 Katsanos, C., Tselios, N., Avouris, N.: AutoCardSorter: Designing the information architecture of a web site using latent semantic analysis. In: Proceedings of the 26th Annual SIGCHI Conference on Human factors in Computing Systems (CHI 2008). ACM Press, New York (2008)

11 Kralisch, A., Yeo, A.W., Jali, N.: Linguistic and cultural differences in information categorization and their impact on website use. In: Proceedings of the 39th Hawaii International Conference on System Sciences (HICSS 2006). IEEE Computer Society, Los Alamitos (2006)

12 Marcus, A.: Global/intercultural user interface design. In: Sears, A., Jacko, J. (eds.) The Human Computer Interaction Handbook, 2nd edn. Lawrence Erlbaum Associates, New York (2003)

13 Petrie, H., Power, C., Song, W.: Internationalization of Websites: Navigation in Chinese and English Language Sites. In: Aykin, N. (ed.) IDGD 2009. LNCS, vol. 5623. Springer, Heidelberg (2009)

14 Qu, W., Sun, X., Nawaz, A., Plocher, T., Clemmensen, T.: Cultural differences between Chinese and Dane in card sorting. In: Proceedings of the 8th Pan-Pacific Conference on Occupational Ergonomics, PPCOE 2007 (2007)

15 Rugg, G., McGeorge, P.: The sorting techniques: a tutorial paper on card sorts, picture sorts and item sorts. Expert Systems 14(2), 80-93 (1997)

16 Tullis, T., Albert, B.: Measuring the user experience. Morgan Kaufmann, San Francisco (2008)

17 Tullis, T., Wood, L.: How many users are enough for a card-sorting study? In: Proceedings of the Usability Professionals Association Conference 2004, Minneapolis, MN, June 7-11 (2004)

18 Wan Abdul Rahim, W.M.I., Noor, N.L.M., Aidid, S.S.S.H.: Culture influences to website information architecture: an empirical investigation. In: Proceedings of Information Technology 2008 (ITSim 2008). IEEE Computer Society, Los Alamitos (2008)

19 Zavod, M.J., Rickert, D.E., Brown, S.H.: The automated card-sort as an interface design tool: a comparison of products. In: Proceedings of the Human Factors and Ergonomics Society 46th Annul Meeting, pp. 646-650 (2002) 